\title{
Periodontal health and esthetic results in impacted teeth exposed by apically positioned flap technique
}

\author{
Iñaki Cercadillo-Ibarguren ${ }^{\text {, }}$ Jordi Gargallo-Albiol ${ }^{2}$, Daniel Abad-Sánchez ${ }^{2}$, José-Javier Echeverría-García ${ }^{3}$, \\ Leonardo Berini-Aytés ${ }^{4}$, Cosme Gay-Escoda ${ }^{5}$
}

${ }^{1}$ DDS. Master in Oral Surgery and Implantology. Associate Professor of Oral Surgery. University of Barcelona Dental School. Investigator of the IDIBELL Institute

${ }^{2}$ DDS, PhD. Master in Oral Surgery and Implantology. Professor of the Master in Oral Surgery and Implantology. University of Barcelona Dental School. Investigator of the IDIBELL Institute

${ }^{3}$ DDS, MD, PhD. Chairman and Full Professor of Periodontology. University of Barcelona Dental School. Investigator of the IDIBELL Institute

${ }^{4}$ DDS, MD, PhD. Maxillofacial Surgeon. Associate Professor of Oral Surgery. Professor of the Master in Oral Surgery and Implantology. University of Barcelona Dental School. Investigator of the IDIBELL Institute

${ }^{5}$ DDS, MD, PhD. Maxillofacial Surgeon. Chairman and Full Professor of Oral and Maxillofacial Surgery Department. Director of the Master of Oral Surgery and Implantology. University of Barcelona Dental School. Head of Oral and Maxillofacial Surgery Department of the Teknon Medical Center. Barcelona (Spain). Investigator of the IDIBELL Institute

Correspondence:

Centro Médico Teknon

Instituto de Investigación IDIBELL

C/Vilana 12

08022 - Barcelona (Spain)

cgay@ub.edu

Received: 06-03-2010

Accepted: $31-05-2010$

\author{
Cercadillo-Ibarguren I, Gargallo-Albiol J, Abad-Sánchez D, Echeverría- \\ García JJ, Berini-Aytés L, Gay-Escoda C. Periodontal health and esthetic \\ results in impacted teeth exposed by apically positioned flap technique. \\ Med Oral Patol Oral Cir Bucal. 2011 Jan 1;16 (1):e89-95. \\ http://www.medicinaoral.com/medoralfree 01/v16i1/medoralv16ilp89.pdf \\ Article Number: 16958 http://www.medicinaoral.com/ \\ (C) Medicina Oral S. L. C.I.F. B 96689336 - pISSN 1698-4447 - eISSN: 1698-6946 \\ eMail: medicina@medicinaoral.com \\ Indexed in: \\ Science Citation Index Expanded \\ Journal Citation Reports \\ Index Medicus, MEDLINE, PubMed \\ Scopus, Embase and Emcare \\ Indice Médico Español
}

\begin{abstract}
Objectives: This study evaluates the periodontal health status and the esthetic results of teeth subjected to orthodontic traction, after their exposure by an apically positioned flap.

Study design: Fifteen patients were included in the study, ages between 11 and 28 years old. The fenestrated teeth and their homologous contralateral normally erupted teeth, used as control, were evaluated.

Results: Statistically significant differences were found in the position of the gingival margin $(p=0.005)$, with an average distance between cemento-enamel junction (CEJ) and gingival margin of $2.47 \mathrm{~mm}$ (SD 1.19) in control teeth and of $1 \mathrm{~mm}$ (SD 1.31) in the operated teeth, and in the depth of palatal probing ( $\mathrm{p}=0.031)$, with $2.1 \mathrm{~mm}$ (SD 0.9 ) for the experimental teeth and $1.7 \mathrm{~mm}$ (SD 0.8) for the control teeth. The gingival index, the bleeding during probing and the probing depth did not show statistically significant differences. The patient's subjective esthetic evaluation was more favorable for the control teeth in most of the cases.

Conclusions: The surgical approach for the impacted teeth by means of the apically positioned flap resulted to be a predictable technique allowing the maintenance of the periodontal health on a long-term basis.
\end{abstract}

Key words: Impacted teeth, surgical exposure, apically positioned flap, periodontal health, periodontal esthetic. 


\section{Introduction}

It is estimated that, without counting third molars, 1.65\% of the patients between 15 and 19 years present impacted teeth. The superior canine is the tooth that is found more frequently impacted in the superior maxillary, with a prevalence of $34 \%$, followed by the third molar and the maxillary central incisor that is retained in $4 \%$ of the occasions. Concerning the patient population that is attended by orthodontists, various studies report the incidence between $2 \%$ and $7 \%$ for upper canines $(1,2)$. Bucal retention of the upper canine is observed in $1-2 \%$ of all patients undergoing orthodontic treatment (3). Classically, three fundamental principles were considered when treating impacted teeth: the surgical approach, the type of fixation that is adhered to the tooth for its posterior traction and the orthodontic movements that have to be applied in order to position the tooth in the dental arch. Additionally, it is necessary to maintain periodontal health of the teeth, eruption of which is carried out using orthodontic forces $(4,5)$. The surgical approach to expose the crown of the impacted tooth on the vestibular side continues to be a topic of discussion in the contemporary dentistry. The techniques described decades ago include the following: conductive alveolotomy, conductive alveolectomy, apically or laterally positioned flap, tooth fenestration with extramucosal traction and tooth fenestration with submucosal traction $(1,6-9)$.

The primary goal of surgical phase is not only to provide the means for correct position of orthodontic anchorage, but also to procure the tooth with favourable tissue anatomy that will permit the long-term maintenance of periodontal health. To achieve the latter, it is convenient to obtain at least 2-3 $\mathrm{mm}$ of keratinized gingival tissue around the tooth $(7,10,11)$. Nevertheless, various authors have demonstrated that gingival tissue can remain healthy with less than $1 \mathrm{~mm}$ of keratinized or adhered gum, and that there is no correlation between the quantity of recession and the width of the adhered gum, thus assuming that the presence of the keratinized band of tissue is not essential for maintaining periodontal health (12-14). Regardless of these relevant conclusions, it has been demonstrated in various controlled clinical long-term studies that the impacted teeth on the vestibular side of the loose alveolar mucosa endure a significant recession and gingivitis when the applied surgical technique is of radical exposure, an approach that does not preserve the keratinized gum around the neck of the tooth $(15,16)$.

The selection of the surgical approach will depend on the position of the impacted tooth in respect to the dental arch and alveolar bone. In any case, it will always be a decision needed to be taken jointly by the orthodontist and the oral surgeon, since the placement of the orthodontic appliance will be equally limited by the surgical approach. In order to improve the eruption prognosis of the tooth as well as its periodontal health, one should keep in mind certain details regarding surgical technique, such as to avoid both the excessive elimination of bone tissue beyond the cemento-enamel junction (CEJ) and the complete abscission of the follicular sac, or to evaluate the possibility of carrying out the repositioning techniques in the teeth which are impacted in an unfavorable position (17).

The objective of the present retrospective study was to evaluate the periodontal health status and the esthetic results of teeth subjected to orthodontic traction after exposure by means of an apically positioned flap.

\section{Materials and Methods}

-Study population

Initially, 22 patients were included in the study, which were referred by the Department of Orthodontics at the University of Barcelona to the Department of Oral Surgery due to the presence of impacted teeth in the vestibular position without possibility of spontaneous eruption. To carry out the surgical intervention, the informed consent of all the patients and of the parents of those patients that were minors was obtained.

The inclusion criteria for this study were: patients with a dental inclusion on the vestibular side that would affect the lateral incisor, canine or premolars, exposed by means of an apically positioned flap and followed by a pertinent orthodontic treatment. In the moment of the clinical evaluation, the patient should have concluded at least 6 months of the orthodontic treatment, and the surgical intervention should have been made at least 18 months prior to evaluation. The exclusion criteria included the presence of impacted central incisors, due to the difficulty of evaluating certain clinical parameters of the experimental tooth and control tooth and the presence of bilateral impacted teeth of the same dental arch due to privation of the control tooth.

Seven patients were excluded from the study since they failed to meet one or more of the mentioned inclusion criteria. The remaining 15 patients, 10 women and 5 men, between 11 and 28 years old (mean age 16.8 years) were included in this study. The experimental teeth corresponded to 7 right superior canines, 5 left superior canines, a left inferior canine, a right inferior canine and a second right superior premolar.

After accomplishing the first visit that included the study and complete examination of the patients, they received an oral prophylaxis.

-Surgical procedure

Surgical technique for exposure of bucally impacted teeth by means of an apically positioned flap, previously described in the literature $(1,7,8)$, was carried out by making two parallel or slightly apically diverging vertical incisions, mesial and distal to the tooth to be exposed, preserving the papillae of the adjacent teeth. Joined horizontally by means of a semilunar incision, 
a full thickness rectangular flap was elevated starting from the edentulous area and continuing until accessing the impacted tooth. The ostectomy was performed with a hand piece and a tungsten carbide burr number 8 until exposing $2 / 3$ of the crown, partially eliminating connective follicular tissue. Finally, the flap folded into "accordion" shape in an apical position, was sutured with silk of $4 / 0$ to the alveolar mucosa, leaving more than half of the crown exposed (Fig. 1).

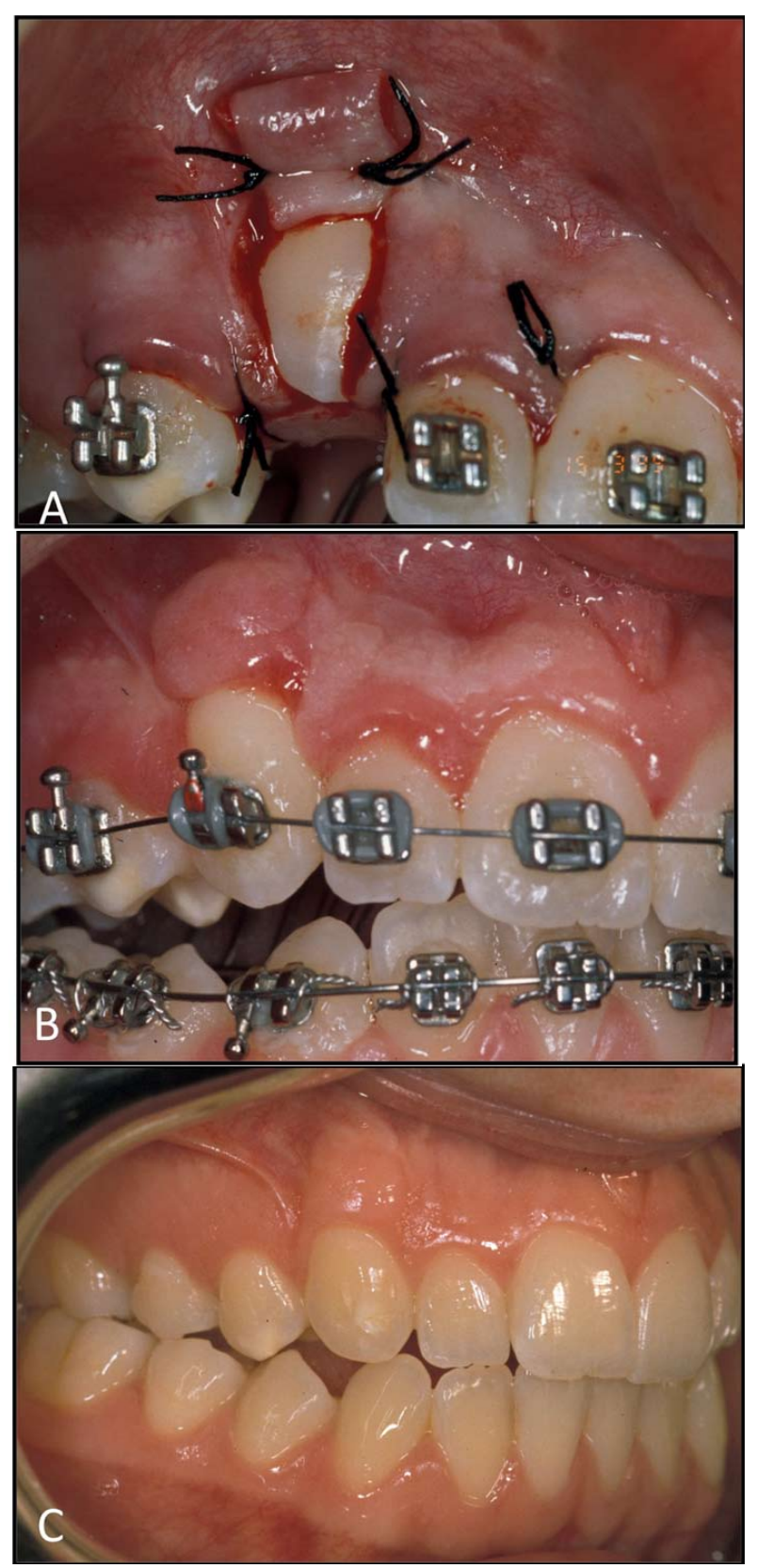

Fig. 1. A) Exposure of an impacted upper canine located on the bucal side by means of an apically positioned flap. B) Clinical view of the soft tissues during the orthodontic traction of the impacted canine.

C) Final appearance of the canine three years after the mucogingival surgery.

\section{-Post-surgical procedure}

An analgesic anti-inflammatory therapy was established with ibuprofen $600 \mathrm{mg}$ every 8 hours during 4 days, and an antibiotic therapy during seven days with amoxicillin $750 \mathrm{mg}$ every 8 hours. The posology was individualized in the pediatric patients depending of the body weight. After 1 week the stitches were removed, meanwhile, great emphasis was placed throughout the treatment on the necessity of maintaining correct oral hygiene, especially of the surgical area by using a soft brush and chlorhexidine mouthwashes $(0.12 \%$ twice a day during 14 days).

\section{-Orthodontic treatment}

At 2 or 3 weeks after the surgical procedure, the orthodontist, after the adhesion of a button or bracket, began the soft and continuous traction of the exposed tooth with forces between 30 and $60 \mathrm{~g}$ (18).

\section{-Periodontal parameters}

In order to evaluate the status of periodontal health of the experimental and control teeth, a single examiner determined the Plaque Index of Quigley and Hein (19), modified by Turesky (20) (IP), from central incisor to the first molar, obtaining the pertinent data of the experimental and control sides. Gingival inflammation was evaluated using the Gingival Index of Löe and Silness (21) (IG), measuring at 4 points in each tooth, 3 on the vestibular side and one on the palatine side. Probing depth (PD) was measured with a manual Michigan "OR" probe at six points on the experimental tooth and control teeth: mesiovestibular, vestibular, distovestibular, distopalatine, palatine and mesiopalatine, and the values were rounded to the nearest $0.5 \mathrm{~mm}$. The bleeding points during probing (BP) were also recorded. The width of keratinized gum (KG) was measured from the gingival margin until the mucogingival junction, rounding the values until the nearest millimeter and using a Michigan "OR" probe with Williams marks. The width of attached gingiva (AG) was calculated by subtracting the depth of vestibular probing from the width of keratinized gingiva. The presence of gingival recession (GR) was detected by measuring the distance from the gingival margin to the CEJ with a Michigan "OR" probe with Williams marks. A negative value represented that the gingival margin was located apically to the CEJ.

\section{-Esthetic parameters}

To evaluate the esthetic results of the experimental and control teeth, the length of the clinical crown (CC) was measured with a gauge, starting at the vestibular side, following the longitudinal axis of the tooth, from the gingival margin to the incisal margin or the cuspid of the tooth. The presence of surgical scars (PS) on the vestibular side of the exposed tooth, mesial and/or distal to the tooth, the changes in the gingival contour (GC), and the changes of gingival coloration (GCL) were also registered. Finally, using non-calibrated visual analog 
scale (VAS), each patient was asked to point out on the line the subjective esthetic evaluation (SE) that he/she would give to each one of the two teeth, test and control, where the beginning of the line would represent an "non-esthetic" tooth with "non-esthetic" gingival contour and the end of the line would represent a "esthetic" tooth and "esthetic" gingival contour.

-Statistical analysis

The inferential analysis to determine the statistically significant differences in the periodontal parameters was performed using non-parametric Wilcoxon signedrank test, with a level of significance of $95 \%(p</=0.05)$. Periodontal esthetic parameters, including presence of scars (PS), changes in gingival contour (GC) and changes in gingival coloration (GCL) were analyzed by means of a descriptive analysis of frequencies. Wilcoxon test was also used to determine the differences between the values of experimental teeth and control teeth in terms of patient's subjective esthetics and the length of clinical crown. The used software was SPSS 11.5.

\section{Results}

-Periodontal parameters

No statistically significant differences were found between the two groups, experimental and control, in the following parameters: plaque index (PI), gingival index (GI), bleeding during probing (BP), the width of keratinized gingival $(\mathrm{KG})$ and the width of attached gingiva (AG). The teeth in the operated group had a significantly deeper probing values on the palatine side $(p=0.031)$ and a significantly smaller distance from the gingival margin to the CEJ ( $\mathrm{p}=0.005)$ (Table 1$)$.

\section{-Esthetic parameters}

No differences were observed in the patient's subjective esthetic parameters, however, the clinical crown was significantly longer in the operated teeth when compared to control teeth $(\mathrm{p}=0.003)$. The presence of scars (PS) appeared in $86.7 \%$ of the experimental teeth, the changes in the gingival contour (GC) showed up in $40 \%$ of the experimental teeth, and the changes in the gingival coloration (GCL) were detected in $6.7 \%$ of the

Table 1. Clinically evaluated parameters and $\mathrm{p}$ values among groups.

\begin{tabular}{|c|c|c|c|c|c|c|c|}
\hline & \multicolumn{3}{|c|}{ Experimental Teeth } & \multicolumn{3}{|c|}{ Control Teeth } & \multirow{2}{*}{$\begin{array}{l}\text { TOTAL } \\
\text { Value } \mathrm{p}\end{array}$} \\
\hline & $\begin{array}{l}\text { Medium } \\
\text { (SD) }\end{array}$ & $\begin{array}{l}\text { Minimum } \\
\text { Maximum }\end{array}$ & $\begin{array}{c}\text { Average } \\
\text { (IQR) }\end{array}$ & $\begin{array}{l}\text { Medium } \\
\text { (SD) }\end{array}$ & $\begin{array}{l}\text { Minimum } \\
\text { Maximum }\end{array}$ & $\begin{array}{c}\text { Average } \\
\text { (IQR) }\end{array}$ & \\
\hline $\begin{array}{l}\text { Plaque Index } \\
(\mathrm{PI})\end{array}$ & $\begin{array}{c}1,79 \\
(0,76)\end{array}$ & $\begin{array}{l}0,67 \\
3,17 \\
\end{array}$ & $\begin{array}{c}1,50 \\
(1,26)\end{array}$ & $\begin{array}{c}1,59 \\
(0,75) \\
\end{array}$ & $\begin{array}{l}0,33 \\
3,00 \\
\end{array}$ & $\begin{array}{c}1,60 \\
(1,00)\end{array}$ & 0,231 \\
\hline $\begin{array}{l}\text { Gingival Index } \\
\text { (GI) }\end{array}$ & $\begin{array}{c}1,13 \\
(0,48)\end{array}$ & $\begin{array}{c}0 \\
2,00\end{array}$ & $\begin{array}{c}1,00 \\
(0,75)\end{array}$ & $\begin{array}{c}0,95 \\
(0,56)\end{array}$ & $\begin{array}{l}0,25 \\
1,75 \\
\end{array}$ & $\begin{array}{c}0,75 \\
(1,00)\end{array}$ & 0,175 \\
\hline \multirow{2}{*}{$\begin{array}{l}\text { Probing Depth }{ }^{\mathrm{a}} \\
\text { (PD) }\end{array}$} & $\begin{array}{c}1,91 \\
(0,72) \\
\end{array}$ & $\begin{array}{l}1,00 \\
3,67 \\
\end{array}$ & $\begin{array}{c}2,00 \\
(1,00)\end{array}$ & $\begin{array}{c}2,22 \\
(0,92)\end{array}$ & $\begin{array}{l}1,00 \\
4,00 \\
\end{array}$ & $\begin{array}{c}2,33 \\
(1,66) \\
\end{array}$ & 0,144 \\
\hline & $\begin{array}{c}2,11 \\
(0,93)\end{array}$ & $\begin{array}{l}1,00 \\
467\end{array}$ & $\begin{array}{c}2,00 \\
(1,00)\end{array}$ & $\begin{array}{c}1,77 \\
(0,85)\end{array}$ & $\begin{array}{l}1,00 \\
3,67\end{array}$ & $\begin{array}{c}1,66 \\
(1,33)\end{array}$ & $0,031 *$ \\
\hline $\begin{array}{l}\text { Bleeding during } \\
\text { Probing }{ }^{\mathrm{b}} \\
\text { (BP) }\end{array}$ & $\begin{array}{c}1,47 \\
(0,99)\end{array}$ & $\begin{array}{l}0 \\
3\end{array}$ & $\begin{array}{c}2,00 \\
(1,00)\end{array}$ & $\begin{array}{c}1,33 \\
(1,45)\end{array}$ & $\begin{array}{l}0 \\
4\end{array}$ & $\begin{array}{c}1,00 \\
(3,00)\end{array}$ & 0,658 \\
\hline $\begin{array}{l}\text { Adhered Gum }{ }^{\mathrm{a}} \\
\text { (AG) }\end{array}$ & $\begin{array}{l}4,08 \\
(2,25)\end{array}$ & $\begin{array}{l}0,67 \\
7,67\end{array}$ & $\begin{array}{c}4,66 \\
(3,33)\end{array}$ & $\begin{array}{c}3,44 \\
(1,64)\end{array}$ & $\begin{array}{l}1,00 \\
6,33\end{array}$ & $\begin{array}{c}3,66 \\
(2,33)\end{array}$ & 0,197 \\
\hline $\begin{array}{l}\text { Keratinized Gum }{ }^{\mathrm{a}} \\
(\mathrm{KG})\end{array}$ & $\begin{array}{c}6,00 \\
(2,56)\end{array}$ & $\begin{array}{c}2 \\
10 \\
\end{array}$ & $\begin{array}{c}6,00 \\
(4,00)\end{array}$ & $\begin{array}{c}5,67 \\
(1,91)\end{array}$ & $\begin{array}{l}2 \\
8\end{array}$ & $\begin{array}{c}6,00 \\
(4,00)\end{array}$ & 0,545 \\
\hline $\begin{array}{c}\text { Presence of } \\
\text { Gingival } \\
\text { Recession }^{\mathrm{a}, \mathrm{d}}(\mathrm{GR})\end{array}$ & $\begin{array}{c}1,00 \\
(1,31)\end{array}$ & $\begin{array}{c}-2 \\
2\end{array}$ & $\begin{array}{c}1,00 \\
(1,00)\end{array}$ & $\begin{array}{c}2,47 \\
(1,19)\end{array}$ & $\begin{array}{l}1 \\
5\end{array}$ & $\begin{array}{c}3,00 \\
(2,00)\end{array}$ & $0,005^{*}$ \\
\hline $\begin{array}{c}\text { Clinical Crown }{ }^{\mathrm{a}} \\
(\mathrm{CC})\end{array}$ & $\begin{array}{c}9,87 \\
(1,92)\end{array}$ & $\begin{array}{c}5 \\
13 \\
\end{array}$ & $\begin{array}{l}10,00 \\
(2,00)\end{array}$ & $\begin{array}{c}8,20 \\
(1,66)\end{array}$ & $\begin{array}{c}5 \\
11 \\
\end{array}$ & $\begin{array}{c}8,00 \\
(2,00)\end{array}$ & $0,003^{*}$ \\
\hline $\begin{array}{l}\text { Subjective } \\
\text { Esthetics }^{c} \\
\quad(\mathrm{SE})\end{array}$ & $\begin{array}{l}5,80 \\
(2,24)\end{array}$ & $\begin{array}{c}2 \\
10\end{array}$ & $\begin{array}{c}6,00 \\
(3,00)\end{array}$ & $\begin{array}{c}7,07 \\
(1,53)\end{array}$ & $\begin{array}{c}5 \\
10\end{array}$ & $\begin{array}{c}7,00 \\
(2,00)\end{array}$ & 0,120 \\
\hline
\end{tabular}

a Values in millimeters.

b Values in number of bleeding points.

c Values in number of points assigned in VAS.

$\mathrm{d}$ Negative values represent that gingival margin is positioned apically to the cemento-enamel juction

* Significant difference between the groups with a p-value $<0.05$ (Wilcoxon test).

v: vestibular p: palatine 
Table 2. Values of the esthetic parameters.

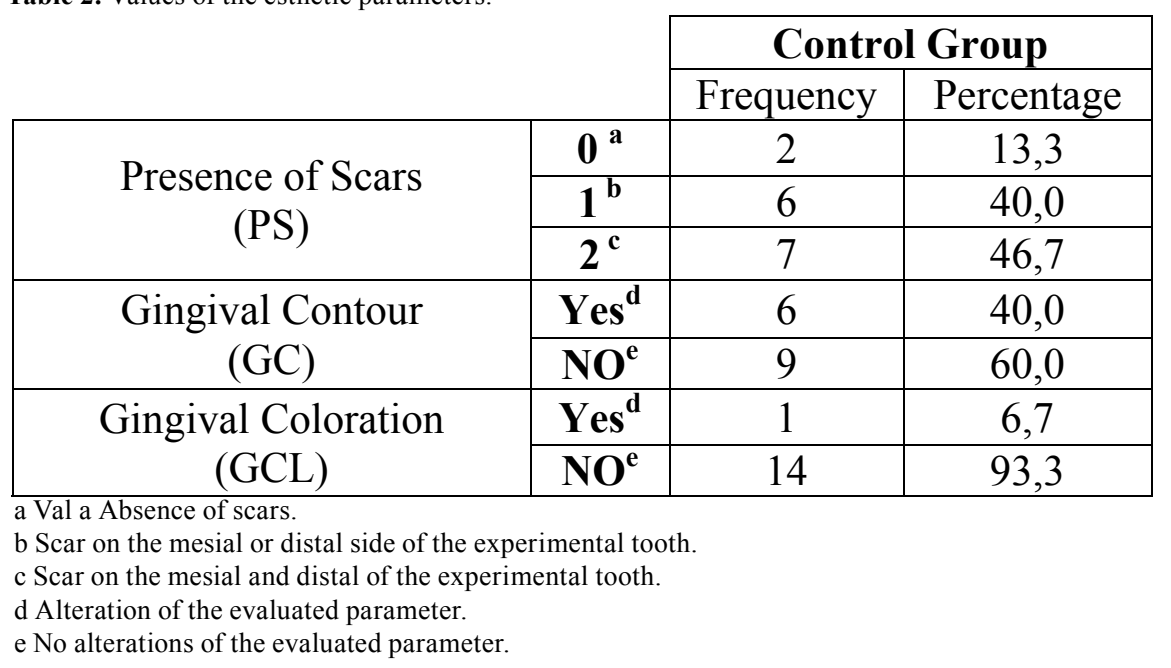

experimental teeth. The parameters PS, GC and GCL remained unaltered in the control teeth (Table 1 and 2).

\section{Discussion}

The results of this study show, in general, that it is possible to maintain periodontal health of teeth exposed by means of an apically positioned flap. No statistically significant differences were found in the parameters of gingival inflammation, quantity of attached gingiva and plaque index between the operated teeth and their contralateral controls. On the other hand, periodontal esthetics, overall, was compromised by the presence of visible scars and, on occasion, by the increased length of the clinical crown.

Other periodontal parameters measured in this study show statistically significant differences, such as the slightly augmented depth of probing on the palatine side of the experimental teeth. The augmented depth of palatine probing is a parameter that has been previously reflected in the literature dealing with the present topic (22). The fact that mucogingival surgery of the impacted canine on the vestibular side does not include exposure on the palatine side might induce an increase in the amount of free gingiva once the tooth is located in the arch, causing an increase in probing values, however, not affecting the insertion of the periodontal supracrestal fibers.

Data from studies such as the one by Vermette et al. (8) coincide with our results, demonstrating that the gingival margin in some of the operated teeth was situated apically relative to the control teeth in a statistically significant manner. The differences registered in our study were, nevertheless, clinically not significant since only three of the operated teeth exhibited the presence of the CEJ on the vestibular side. In contrast, these findings are different from those presented in the report by Vanarsdall and Corn (7), who did not encounter differences in the position of the gingival margin on the vestibular side of the teeth treated by means of the apically positioned flap.

The length of the clinical crown of the operated teeth was also superior to the control teeth. This variable is rarely evaluated, only Vermette et al. (8) included it in their study and obtained the results comparable to the ones presented in this study. The exposure of the CEJ as well as the apical position of the gingival margin and a marked increase in the clinical crown produced an unequal gingival margin, possibly resulting unaesthetic in patients with a high smile line.

The presence of gingival scars was frequently observed in our study. In the present study, $86.7 \%$ of operated teeth exhibited some degree of scarring, and $46.7 \%$ showed the presence of a bilateral scar in the soft tissues, mesial and distal to the tooth intervened surgically. These data are similar to those reported in the literature (8) who encountered that $90 \%$ of the teeth operated using the technique of the apically positioned flap presented visible scars. The alterations in the gingival contour were evidenced in $40 \%$ of the experimental teeth, revealing a gingival enlargement in the anteroposterior side, similarly to the results shown by Becker et al. (23), who reported it in $33 \%$ of their cases. Regardless, these data cannot be equally compared since the cases in their study concerned the impacted teeth on the vestibular side and treated using the technique of submucosal traction. The alterations in the gingival coloration were only encountered in one case, which displayed reddish color of the keratinized gingiva that was not appreciable 
in the remaining teeth, neither in the control tooth nor caused by gingivitis in other teeth. This situation could arise due to the fact that the loose alveolar mucosal tissue is pooled from the apical position together with the flap sutured to the end of the tooth in the arch.

Patient's evaluation of esthetic results was carried out by means of an Analogical Visual Scale (VAS) test (24). According to our literature search, VAS has not been applied for evaluation of the results after the procedure of exposing impacted teeth. Although the differences among the groups of teeth were not statistically significant, the average mark for the experimental group was of 5.80 and for the control group of 7.07. A lower mark in the experimental tooth was related, according to patient's comments, to an excessive size of the clinical crown, especially noticeable in teeth with an exposed CEJ. In none of the cases the patients commented on the non-esthetic aspect of the scars, however, they did give importance to the alteration of the gingival contour in the experimental teeth.

Certain reports in literature compare the submucosal traction and the apically positioned flap techniques as the means for the exposure of impacted teeth on the vestibular side. These studies argue for the use of submucosal traction as a selected approach since it is similar to the physiological eruption of the tooth, not mentioning, however, that results concerning periodontal health as well as esthetics are more advantageous with a surgical approach (8). These authors found a bigger loss of vestibular periodontal insertion in the teeth treated with the apically positioned flap followed by extramucosal traction, in comparison with the teeth treated by means of orthodontic submucosal traction. They explain this fact suggesting that impacted teeth have on the vestibular side a thinner vestibular cortical bone and, therefore, present more risk of loss of attachment if an apically positioned flap is carried out.

In contrast, various studies have supported the technique of the apically positioned flap, since it is possible to overcome the obstacle of the role of mucosa in the eruption of the tooth, diminishing the reinterventions necessary with this technique in comparison with surgical technique used for submucosal traction. Unlike the technique for submucosal traction, the apically positioned flap approach also facilitates the preservation of the adequate quantity of keratinized gingiva that will avoid marginal bone loss and gingival recession $(7,25,26)$.

Our study shows that the apically positioned flap to expose impacted teeth is a valid and effective technique that, furthermore, facilitates long-term maintenance of periodontal health. However, esthetics can be compromised by the presence of visible scars and, in some cases, by longer clinical crowns.

\section{References with links to Crossref - DOI}

\section{References}

1. Kokich VG, Mathews DP. Surgical and orthodontic management of impacted teeth. Dent Clin North Am. 1993;37:181-204.

2. Parkin N, Benson PE, Thind B, Shah A. Open versus closed surgical exposure of canine teeth that are displaced in the roof of the mouth. Cochrane Database Syst Rev. 2008;4:CD006966.

3. Johnston WD. Treatment of palatally impacted canine teeth. Am J Orthod. 1969;56:589-96.

4. Frank CA, Long M. Periodontal concerns associated with the orthodontic treatment of impacted teeth. Am J Orthod Dentofacial Orthop. 2002;121:639-49.

5. Pini Prato G, Baccetti T, Magnani C, Agudio G, Cortellini P. Mucogingival interceptive surgery of buccally-erupted premolars in patients scheduled for orthodontic treatment. I. A 7-year longitudinal study. J Periodontol. 2000;71:172-81.

6. Wisth PJ, Norderval K, Boe OE. Periodontal status of orthodontically treated impacted maxillary canines. Angle Orthod. 1976;46:6976.

7. Vanarsdall RL, Corn H. Soft-tissue management of labially positioned unerupted teeth. Am J Orthod. 1977;72:53-64.

8. Vermette ME, Kokich VG, Kennedy DB. Uncovering labially impacted teeth: apically positioned flap and closed-eruption techniques. Angle Orthod. 1995;65:23-32.

9. Chaushu S, Dykstein N, Ben-Bassat Y, Becker A. Periodontal status of impacted maxillary incisors uncovered by 2 different surgical techniques. J Oral Maxillofac Surg. 2009;67:120-4.

10. Pini Prato G, Baccetti T, Giorgetti R, Agudio G, Cortellini P. Mucogingival interceptive surgery of buccally-erupted premolars in patients scheduled for orthodontic treatment. II. Surgically treated versus nonsurgically treated cases. J Periodontol. 2000;71:182-7.

11. Lang NP, Löe H. The relationship between the width of keratinized gingiva and gingival health. J Periodontol. 1972;43:623-7.

12. Freedman AL, Salkin LM, Stein MD, Green K. A 10-year longitudinal study of untreated mucogingival defects. J Periodontol. 1992;63:71-2.

13. Tenenbaum H. A clinical study comparing the width of attached gingiva and the prevalence of gingival recessions. J Clin Periodontol. 1982;9:86-92.

14. Wennström JL. Lack of association between width of attached gingiva and development of soft tissue recession. A 5-year longitudinal study. J Clin Periodontol. 1987;14:181-4.

15. Tegsjö U, Valerius-Olsson H, Andersson L. Periodontal conditions following surgical exposure of unerupted maxillary canines--a long term follow-up study of two surgical techniques. Swed Dent J. 1984;8:257-63.

16. Wisth PJ, Norderval K, Boe OE. Periodontal status of orthodontically treated impacted maxillary canines. Angle Orthod. 1976;46:6976.

17. Burden DJ, Mullally BH, Robinson SN. Palatally ectopic canines: closed eruption versus open eruption. Am J Orthod Dentofacial Orthop. 1999;115:640-4.

18. Crescini A, Baccetti T, Rotundo R, Mancini EA, Prato GP. Tunnel technique for the treatment of impacted mandibular canines. Int J Periodontics Restorative Dent. 2009;29:213-8.

19. Quigley GA, Hein JW. Comparative cleansing efficiency of manual and powerbrushing. J Am Dent Assoc. 1962;65:26-9.

20. Turesky S, Gilmore ND, Glickman I. Reduced plaque formation by the chloromethyl analogue of victamine C. J Periodontol. 1970;41:41-3.

21. Loe H, Silness J. Periodontal disease in pregnancy. I. Prevalence and Severity. Acta Odontol Scand. 1963;21:533-51.

22. Zasciurinskiene E, Bjerklin K, Smailiene D, Sidlauskas A, Puisys A. Initial vertical and horizontal position of palatally impacted maxillary canine and effect on periodontal status following surgicalorthodontic treatment. Angle Orthod. 2008;78:275-80.

23. Becker A, Brin I, Ben-Bassat Y, Zilberman Y, Chaushu S. Closed-eruption surgical technique for impacted maxillary incisors: 
a postorthodontic periodontal evaluation. Am J Orthod Dentofacial Orthop. 2002;122:9-14.

24. Roccuzzo M, Bunino M, Needleman I, Sanz M. Periodontal plastic surgery for treatment of localized gingival recessions: a systematic review. J Clin Periodontol. 2002;29 Suppl 3:178-94.

25. Bishara SE. Impacted maxillary canines: a review. Am J Orthod Dentofacial Orthop. 1992;101:159-71.

26. Pascual Gil JV, Marqués Mateo M, Puche Torres M, Miragall Alba L, Iglesias Gimilio ME, Villar Puchades R. The meridian incision: a technical modification in the conservative surgery of the impacted maxillary canine. Med Oral Patol Oral Cir Bucal. 2008;13:E36-8. 